\title{
An unusual case of a neonate with left sided type 3 poland syndrome with dextrocardia
}

\begin{abstract}
Poland syndrome (PS) is right sided in 75 percent of cases. Only 10 percent are associated with dextrocardia. It is usually detected late for the milder nature of the condition. Only in severe cases it comes to attention during neonatal period. Left sided Poland syndrome with dextrocardia is extremely rare. To the best of our knowledge this is the first case of left sided type 3 Poland syndrome with dextrocardia diagnosed at birth with chest wall getting sucked in and bulging out during inspiration and expiration respectively.
\end{abstract}

Keywords: poland syndrome, dextrocardia, neonate

\author{
Volume 7 Issue 5 - 202I \\ Showkat Hussain Tali,' Mohd Ashraf Bhat,' \\ Zul Eidain Hassan, ${ }^{2}$ Jawaid Haasan Dag, ${ }^{3}$ \\ Shagufta Yousuf, ${ }^{4}$ Sheikh Mushtaq Ahmad' \\ 'Assistant Professor Pediatrics GMC Anantnag, India \\ ${ }^{2}$ Senior Resident Pediatrics GMC Anantnag, India \\ ${ }^{3}$ Senior Resident Radiology GMC Anantnag, India \\ ${ }^{4}$ Medical officer/ gynecologist Health services Kashmir, India
}

Correspondence: Showkat Hussain Tali, Assistant Professor Pediatrics GMC Anantnag, India, Email drshowkatshifa@gmail.com

Received: September II, 2021 | Published: November 01, 2021

\section{Case history}

A full term, male infant, born out of consanguineous marriage at a sub district hospital in south Kashmir with no significant perinatal history or family history of anatomical deformity, was referred to our hospital immediately after birth for incidental finding of left sided chest wall abnormality. Infant was clinically stable with no respiratory distress. On inspection there was left sided chest wall sagging, absent breast nodule and breast tissue, ill developed left anterior axillary fold and two visible dimples in the precordial area (Figure 1). Chest wall at the site of dimples would get sucked in and would bulge out during inspiration and expiration respectively.

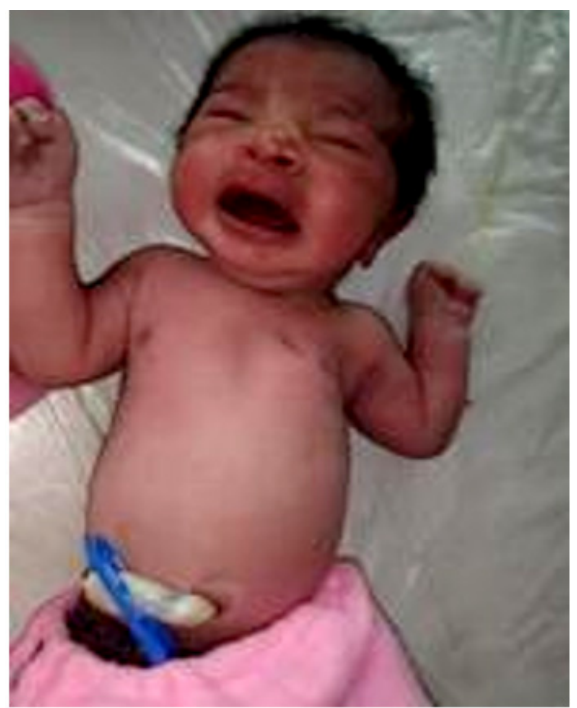

Figure I On inspection there was left sided chest wall sagging, absent breast nodule and breast tissue, ill developed left anterior axillary fold and two visible dimples in the precordial area.

On palpation at the dimple areas, instead of ribs, only soft tissue could be palpated. Left arm and forearm and the fingers of the left hand were relatively shorter without any evidence of symbrachydactyly or any other major abnormality (Figure 2). On auscultation heart sounds were more prominent on right side. X-ray chest was performed and it revealed dextrocardia with intact posterior rib cage with no associated spinal defect or any other significant bony abnormality (Figure 3). Abdominal ultrasonography was unremarkable. USG chest revealed absent left pectoralis major muscle (Figure 4).

Echo cardiography revealed structurally normal heart. A diagnosis of left sided type 3 Poland syndrome with dextrocardia was made. As the diagnosis was evident from clinical examination, X-ray findings and ultrasonography, CT scan chest was not performed to avoid high radiation exposure and for the expected low yield for additional significant findings. Patient was kept in neonatal nursery and was fed orally under supervision. After tolerating oral feeds and passing urine and stools, baby was discharged after 24 hours of admission from neonatal nursery and was kept with mother for further care.

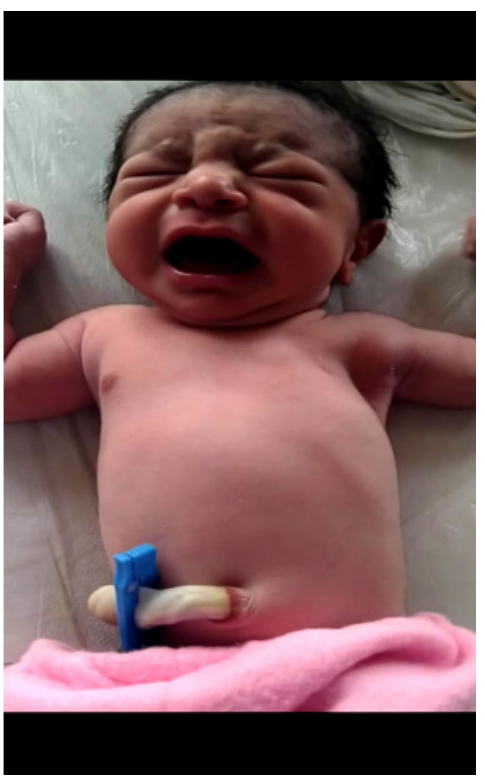

Figure $\mathbf{2}$ Left arm and forearm and the fingers of the left hand were relatively shorter without any evidence of symbrachydactyly or any other major abnormality. 


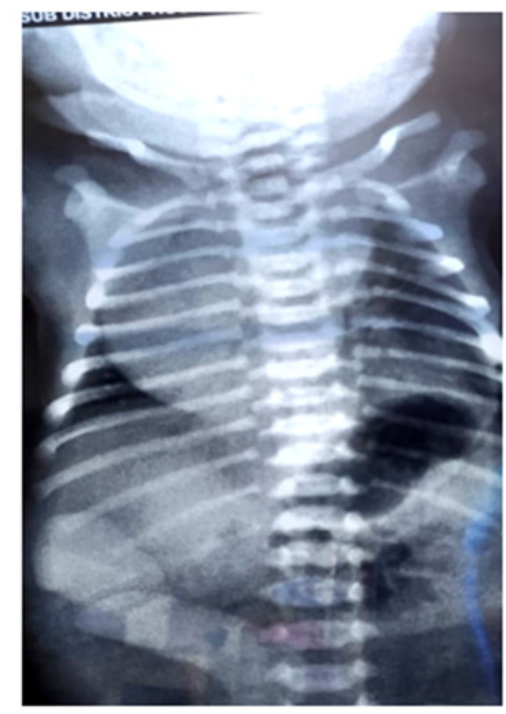

Figure 3 On auscultation heart sounds were more prominent on right side. X-ray chest was performed and it revealed dextrocardia with intact posterior rib cage with no associated spinal defect or any other significant bony abnormality.

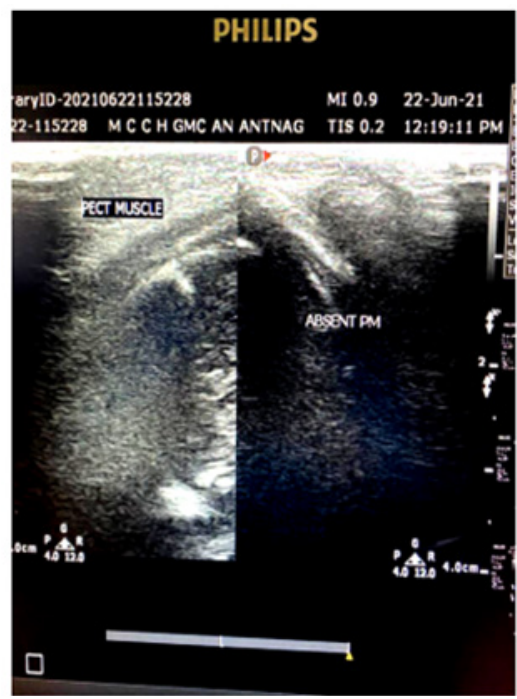

Figure 4 Abdominal ultrasonography was unremarkable. USG chest revealed absent left pectoralis major muscle.

\section{Discussion}

During cadaveric dissection a medical student named Alfred Poland discovered an unusual chest wall anomaly and published it in Guy's Hospital Gazette. He specifically noted absence of the sternocostal portion of the pectoralis major muscle with an intact clavicular origin, absence of the pectoralis minor muscle, and hypoplastic serratus anterior and external oblique muscles. He described these findings in the paper entitled, "Deficiency of the pectoral muscles." The term "Poland syndrome" was coined later by Patrick Clarkson in 1962, a New Zealand-born British plastic surgeon working at Guy's Hospital and Queen Mary's Hospital, London. He noticed that three of his patients had both a hand deformity and an underdeveloped breast on the same side. Clarkson found a reference to a similar deformity published by Alfred Poland and was able to find the hand specimen dissected by Poland, which was still held in the hospital pathology museum.
Poland syndrome or Poland sequence with unknown etiology is variously described to have an incidence of $1: 10,000$, to $1: 100,000$ with a male preponderance of $3: 1$ to $5: 1$. Out of every 4 cases, 3 cases $(75 \%)$ happen to be on right side. About $10 \%$ of the cases are associated with dextrocardia. Dextrocardia when present is associated with complete or partial defect of 2 or more ribs. Left sided Poland syndrome with dextrocardia is extremely rare and less than 60 cases have been described in literature till date. ${ }^{1-4}$ Our case was a male neonate with left sided Poland syndrome with partial defect of two left sided anterior ribs with dextrocardia. In our case it was observed that chest wall would get sucked in and would bulge out during inspiration and expiration respectively which probably has not been described in literature till date.

Depending upon the severity there are 3 types of Poland syndrome. In type 1 or minimal form there is an isolated pectoral muscle defect. Type-2 or partial form has a pectoral muscle defect associated with either upper limb (2a, upper limb variant) or rib ( $2 b$, thoracic variant) anomaly. Type 3 (complete form) is characterized by pectoral muscle defect associated with both upper limb and rib anomalies or defects. ${ }^{2,5}$ Our case was a type 3 Poland syndrome as there was pectoralis major defect associated with rib abnormality and upper limb defect.

Although autosomal dominant and recessive patterns are described in literature but Poland syndrome is typically sporadic and perhaps multi-factorial with low recurrence risk. As many as $4 \%$ cases are familial. ${ }^{6}$ Apart from history of consanguinity, there is nothing to suggest of a Mendelian or familial inheritance in our case.

Evidence indicates that PS results from a vascular developmental anomaly during the critical sixth week of gestation, with hypoplasia of the subclavian artery causing musculoskeletal malformations. That explains why Poland syndrome with Dextrocardia is associated with a specific sequence of anomalies and is generally not associated with other systemic anomalies like gut malrotation..$^{7-9}$ In our case too there was neither a clinical evidence nor a radiological feature that would suggest a gut anomaly like malrotation.

As a significant proportion of PS is of minimal form (type 1), diagnosis is often missed till adolescence or adulthood. Cases with increased severity come to attention in early part of life. ${ }^{10}$ As our case was type 3(complete form), we were able to diagnose it on the day of birth only.

\section{Conclusion}

Poland syndrome is a rare disorder. Left sided Poland is rarer and it is extremely rare occurrence when left sided Poland syndrome is associated with dextrocardia. And probably this is the first case of left sided type 3 Poland syndrome with dextrocardia, presenting at birth, where lungs get sucked in and bulge out during inspiration and expiration respectively.

\section{Acknowledgments}

None.

\section{Conflicts of interest}

The authors declare that they have no competing interests.

\section{Funding}

None. 


\section{References}

1. Cinjel V, Bohac M, Mestanova V, et al. Poland syndrome: from embryological basis to plastic surgery. Surg Radiol Anat. 2013;35(8):639646.

2. Divizia MT, Leroni M , Pulity A, et al. Orphanet: The portal for rare diseases and orphan drugs. 2020.

3. Freire-Maia N, Chautard EA, Opitz JM, et al. The Poland syndromeclinical and genealogical data, dermatoglyphic analysis, and incidence. Hum Hered. 1973;23(2):97-104.

4. Ozkok S, Erol N, Onal C, et al.Left-sided Poland's syndrome associated with dextrocardia. North Clin Istanb. 2019;6(2):192-195.

5. Romanini MV, Torre M, Santi P, et al. Proposal of the TBN Classification of Thoracic Anomalies and Treatment Algorithm for Poland Syndrome. Plast Reconstr Surg. 2016;138(1):50-58.
6. CM Tassano E, Torre M, Gimelli S, et al. Assessment of copy number variations in 120 patients with Poland syndrome. BMC Medical Genetics. 2016;17:89.

7. Yiyit N, Işıtmangil T, Öksüz S . Clinical analysis of 113 patients with Poland syndrome. Ann Thorac Surg. 2015;99(3):999-1004.

8. Bavinck JN, Weaver DD. Subclavian artery supply disruption sequence: hypothesis of a vascular etiology for Poland, Klippel-Feil, and Mobius anomalies. Am J Med Genet. 1986;23(4):903-918.

9. Lerone M, Seri M, Boffi P. Lower extremity counterpart of the Poland syndrome. Clin Genet. 1999;55(1):41-43.

10. Buckwalter V JA, Shah AS. Presentation and Treatment of Poland Anomaly. Hand (N Y). 2016;11(4):389-395. 